\title{
Speciation of two stingrays with antitropical distributions: low levels of divergence in mitochondrial DNA and morphological characters suggest recent evolution
}

\author{
A. Le Port ${ }^{1,2, *}$, M. D. M. Pawley ${ }^{3}$, S. D. Lavery ${ }^{1,2}$ \\ ${ }^{1}$ Leigh Marine Laboratory, University of Auckland, PO Box 349, Warkworth 0941, New Zealand \\ ${ }^{2}$ School of Biological Sciences, University of Auckland, Private Bag 92019, Auckland, New Zealand \\ ${ }^{3}$ Institute of Information and Mathematical Sciences, Massey University, Auckland 0745, New Zealand
}

\begin{abstract}
Disjunct geographic distributions across the equator (antitropicality) occur in many marine and terrestrial taxa. However, their origin and role in forming new species is still poorly understood. Here we examine the phylogenetic relationships and levels of genetic and morphological divergence in 2 stingray species, the Southern Hemisphere Dasyatis brevicaudata and the Northern Hemisphere D. matsubarai, with antitropical distributions and suspected conserved morphological traits. Analyses of concatenated mtDNA sequences (3160 bp dataset: CO1, cytochrome $b$, control region) suggest $D$. brevicaudata and $D$. matsubarai are closely related sister lineages, with low levels of sequence divergence more akin to intra- rather than interspecific comparisons. Multivariate analyses of morphological traits are largely consistent with the genetic data in showing small but discrete differences in morphometric characteristics, allowing Northern and Southern Hemisphere individuals to be separated into 2 groups. We suggest that $D$. brevicaudata and $D$. matsubarai are closely related sister taxa that may represent an early stage in the process of allopatric speciation.
\end{abstract}

KEY WORDS: Antitropical distribution $\cdot$ Stingray $\cdot$ Allopatric speciation $\cdot$ Dasyatis $\cdot$ Sister taxa

\section{INTRODUCTION}

The occurrence of the same organisms to the north and south of the tropical zone but not within the tropics has been coined an antitropical (or amphitropical) distribution (Hubbs 1952). Disjunct distributions of taxa across the tropics are observed for a variety of organisms, both terrestrial and aquatic, at various taxonomic, geographic, and presumably historic scales (Randall 1981, Burridge 2002). Over time, they are likely to result in allopatric speciation as genetic and phenotypic differences accumulate between populations, leading to reproductive isolation. The origins of such distributions are intriguing: How did taxa apparently intolerant to tropical conditions (i.e. temperate species) become represented in both Northern and Southern Hemispheres (Briggs 2003)? Several mechanisms have been proposed for the development of antitropical distributions, from dispersal and vicariance events (Burridge 2002), to the 'tropical extinction hypothesis' (Briggs 2003). The majority of examples of antitropicality in the literature deal with fish species with long-lived larval stages and/or mobile pelagic adults (Graves 1998, Burridge 2002), for which dispersal is often strongly influenced by currents, and long-distance deep water crossings are not an obstacle. However, little attention has been given to the dispersal patterns and resulting antitropical distributions of more shallowwater or coastal live-bearing species such as elasmo- 
branchs (sharks and rays), which rely mostly on the active dispersal of adults and juveniles, and are mostly limited to the continental shelf in their movements. There are a few documented examples of elasmobranchs with such life histories with antitropical distributions either side of the equator, e.g. spiny dogfish Squalus acanthias and bronze whaler shark Carcharhinus brachyurus (Compagno et al. 2005). Despite the commercial importance of some of these taxa, very little work has been done describing the potential dispersal mechanisms leading to their antitropical distributions (Ward et al. 2008b, Veríssimo et al. 2010, Benavides et al. 2011). Recent molecular work on the evolutionary dispersal of coastal shark species with disjunct distributions has proposed a stepping-stone model of dispersal for these species (Duncan et al. 2006, Keeney \& Heist 2006, Benavides et al. 2011).

Although phylogenetic relationships can be reconstructed from a variety of characters, including morphological features, molecular data are particularly applicable for taxa that have diverged recently and exhibit limited variation in morphological traits (Avise 1994). Morphological phylogenetic studies can be hindered in the resolution of relationships between taxa by the difficulty in defining the polarity of morphological character states. This is often due to a very poor fossil record, many instances of parallel evolution and a lack of understanding of the character states of plesiomorphic outgroup taxa (Martin 1995). Furthermore, elasmobranchs and more specifically batoids (skates and rays), appear to be subject to a high level of morphological conservatism (McEachran \& Dunn 1998). Molecular phylogenetic analysis may be the only means to confidently infer systematic relationships of chondrichthyian fishes (Martin 1995), and mitochondrial-encoded genes have proven valuable as a source of characters for inferring phylogenetic relationships in elasmobranchs (Kitamura et al. 1996, Douady et al. 2003, Dunn et al. 2003, Human et al. 2006, Rocco et al. 2007, Pasolini et al. 2011). Mitochondrial DNA (mtDNA) offers a particularly rich source of markers for the study of closely related taxa largely because of the reduced effective population size and relatively fast rate of sequence evolution (Chow \& Kishino 1995). To account for issues like stochastic lineage sorting in single loci, the addition of nuclear DNA data is preferable, when possible, although this has proved difficult for elasmobranchs.

Stingrays (family Dasyatidae) are most diverse and abundant in coastal tropical and warm temperate waters worldwide. This family currently comprises at least 9 genera (Dasyatis, Taeniura, Pteroplatytrygon, Makarararja, Neotrygon, Himantura, Urogymnus, Pastinachus, and Taeniurops) and about 79 currently recognised species, most of which are found in the Indo-West Pacific (Last \& Stevens 2009; W. White pers. comm.). The short-tailed stingray Dasyatis brevicaudata (Hutton 1875) has a disjunct Southern Hemisphere range with centres of distribution in the southwest Pacific (New Zealand/eastern Australia), eastern Indian Ocean (western Australia), and western Indian Ocean/southeast Atlantic (South Africa) (Compagno et al. 1989, Last \& Stevens 2009). Recent molecular work using the rapidly evolving mtDNA control region has confirmed that $D$. brevicaudata populations from across the Southern Hemisphere belong to a single species, but has also shown considerable isolation between these regions (Le Port \& Lavery 2012). Interestingly, this ray is morphologically very similar and shares several unique key morphological characters with the pitted stingray $D$. matsubarai (Miyosi 1939), which is a Northern Hemisphere species found in the warm temperate to subtropical waters of the northwest Pacific and Sea of Japan (Japan, Korea) (Nishida \& Nakaya 1990, Lee \& Joo 1996). Preliminary phylogenetic analyses of 11 Dasyatis species using mitochondrial 16S, cytochrome $c$ oxidase subunit 1 (CO1) and cytochrome $b$ (cytb) sequences suggest that $D$. brevicaudata and $D$. matsubarai are closely related (Le Port 2009). With no apparent overlap in their distributions across the tropics, it is an open question as to whether D. matsubarai and $D$. brevicaudata are antitropical species (or subspecies) resulting from the dispersal and/or vicariant event of an ancestral, perhaps tropical species, or whether they are phenotypically similar but distinct species due to the parallel or convergent evolution of separate ancestral species.

The aims of this research were to clarify the phylogenetic evolutionary relationships between $D$. brevicaudata and the morphologically similar $D$. matsubarai. To address these aims, previous analyses of $D$. brevicaudata mtDNA control region sequences (Le Port \& Lavery 2012) were combined with new data: control region sequences from $D$. matsubarai; sequence data from both species for 2 additional mtDNA markers (CO1, cytb); and comprehensive morphometric and meristic data from both species. More specifically we asked: (1) Do molecular and morphological data allow us to unambiguously discriminate $D$. brevicaudata and D. matsubarai?; (2) Does this data support $D$. brevicaudata and D. matsubarai as sister species?; and (3) What biogeographic scenario might best explain their current distributions? 


\section{MATERIALS AND METHODS}

\section{Molecular data}

Taxon sampling

Dasyatis brevicaudata samples were collected from several locations throughout the species' range, while D. matsubarai samples were collected from 2 locations in Japan (JPN), $1000 \mathrm{~km}$ apart (Fig. 1, Table S1 in the Supplement at www.int-res.com/ articles/suppl/b019p153_supp.pdf). Samples were collected as skin/muscle tissue from the wild using a biopsy dart fixed on a modified biopsy pole while on SCUBA, caught on rod and reel, or from research collection trips. For animals kept in captivity, a small section of the ventral tail fold was cut with a scalpel, or blood samples were taken and preserved on Whatman FTA cards. Tissue samples were stored in 95\% ethanol at $-20^{\circ} \mathrm{C}$. Details of the individuals sequenced in this study are provided in the Supplement (Table S1), including details of all related outgroups used (D. thetidis, D. lata, D. sabina).

DNA extraction, amplification, and sequencing

Total genomic DNA extraction, amplification, and sequencing procedures follow Le Port \& Lavery (2012). Amplification of partial fragments of mitochondrial genes was performed by PCR (Saiki et al. 1988). The following primers were used for amplification and sequencing: for CO1: Fish-F2 (5'-TCG

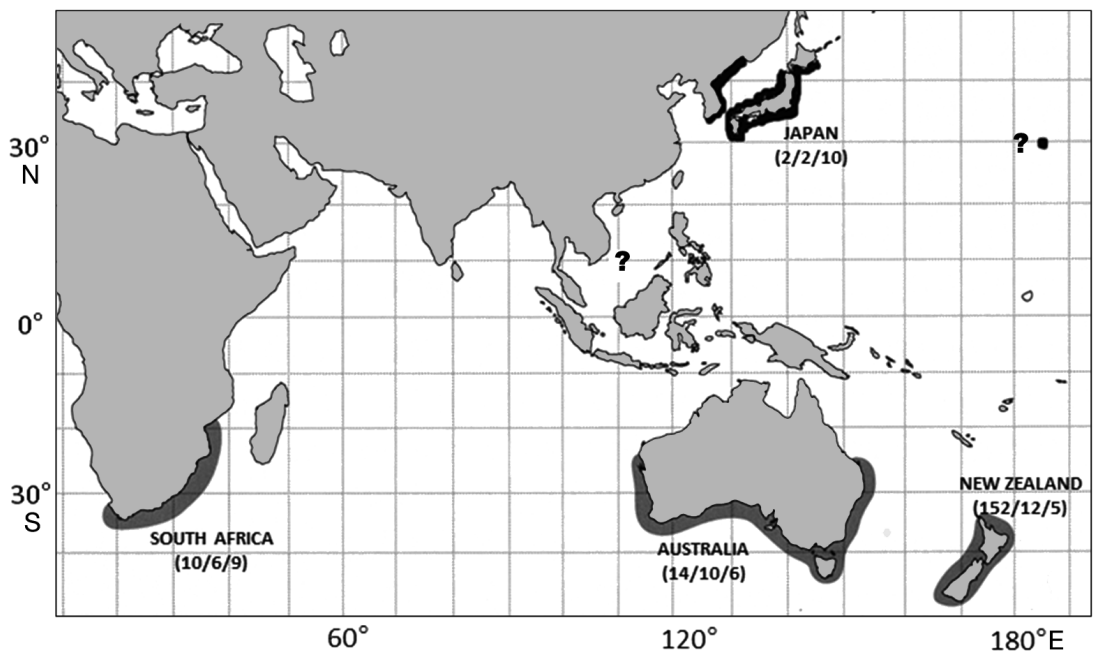

Fig. 1. Geographic distribution and sampled populations of Dasyatis brevicaudata (grey) and D. matsubarai (black). Numbers in brackets represent the control region (dloop) dataset sample size/3160 bp dataset sample size/morphometric dataset sample size. '?' indicate locations where $D$. matsubarai have been reported but not confirmed
ACT AAT CAT AAA GAT ATC GGC AC-3') and Fish-R2 (5'-ACT TCA GGG TGA CCG AAG AAT CAG AA-3') (Ward et al. 2005); cytb: CB2 (5'-CCC TCA GAA TGA TAT TTG TCC TCA-3'), CB3 (5'GGC AAA TAG GAA RTA TCA TTC-3'), and GLUDG (5'-TGA CTT GAA RAA CCA YCG TTG-3') (Palumbi 1996); and the entire control region (dloop): Pro_dasyatis1 (5'-GTC TTG TAA ACC GAA GAG CAG AG-3') /CR_Middle_R (5'-TAT GCC TTA CAA GGG AAC TAG ACC-3') pair and CR_Middle_F (5'- GGT TGG CAC TTT ATC TGG TCT AGT-3') /Phe_dasyatis1 (5'- TAA TAC CAG GTT ATG GAG GCG TGT -3') pair (Le Port \& Lavery 2012). Annealing temperatures for CO1, cytb and dloop were 54, 57 and $60^{\circ} \mathrm{C}$, respectively. Two Dasyatis matsubarai samples were sequenced for all 3 loci. D. brevicaudata sample sizes varied for each mtDNA locus. A total of 176 previously published D. brevicaudata samples (New Zealand, NZ, n = 152; Australia, AUS, $\mathrm{n}=14$; and South Africa, $\mathrm{SA}, \mathrm{n}=10$ ) were used in the analyses of control region sequences (Le Port \& Lavery 2012). A representative selection of these samples were sequenced for cytb and CO1. For cytb, 28 samples ( $\mathrm{NZ}=12$, AUS $=10$ and $\mathrm{SA}=6$ ) were sequenced. A total of $32 \mathrm{D}$. brevicaudata sequences $(\mathrm{NZ}=14, \mathrm{AUS}=12$ and $\mathrm{SA}=6)$ were used in the separate CO1 analyses. The dataset comprising the concatenation of the sequences from these 3 mtDNA loci (CO1-cytb-dloop) is hereafter referred to as the 3160 bp dataset and consisted of 30 sequences in total: $D$. brevicaudata, $\mathrm{n}=28$ (NZ $=12, \mathrm{AUS}=10$ and $\mathrm{SA}=6$ and $D$. matsubarai $(\mathrm{n}=2)$. After considerable efforts, we had no success in amplifying nuclear genes from these species.

\section{Sequence alignment}

All sequences were aligned using Sequencher v.4.7 (Gene Codes) and alignment results confirmed by eye. Species represented by multiple specimens were manually examined for variable sites in order to control for intraspecific variation. Identical sequences were collapsed into a single operational taxonomic unit (OTU) for phylogenetic analyses. Final consensus sequences from each gene were aligned using the ClustalW program of MEGA v. 4.0 (Tamura et al. 2007). After final trimming so that all sequences within each dataset were of 
equal length, the cytb, CO1 and dloop partitions contained 558, 623 and 1979 characters, respectively.

\section{Morphological and meristic data}

Taxon sampling

Distinguishing morphological characters for Dasyatis brevicaudata from other dasyatids include, but are not restricted to: a row of small white spots at the base of each pectoral fin, a bluntly angular snout, a thick base to a whip-like tail which is the same length or shorter than the body in adult specimens, the presence of an 'omega shaped' coracoid groove on the ventral surface, a small dorsal keel and ventral finfold, and the absence of thorn-like denticles along the dorsal midline of the disc (smooth disc) (Figs. 2a,c,e). D. matsubarai possesses D. brevicaudata's typical key characters, namely a row of small white spots at the base of each pectoral fin, and an 'omega shaped' coracoid groove on the ventral surface (Figs. 2b,d,f) (Nishida \& Nakaya 1990). Thus, there are at present no clear morphological distinctions between the 2 species' taxonomic descriptions. A total of 43 morphometric parameters were obtained from 30 specimens (D. brevicaudata $\mathrm{n}=20, D$. matsubarai $\mathrm{n}=10$ ) deposited in the collections of the Te Papa National Museum, Wellington (voucher code: P, DMN); CSIRO Museum, Hobart (H, CA); South African Museum, Cape Town (SAM); South African Institute for Aquatic Biology, Grahamstown (SAIAB); and Hokkaido University Museum, Hakodate, Japan (HUMZ). Meristic counts were recorded for 27 individuals $(D$. brevicaudata $\mathrm{n}=17, D$. matsubarai $\mathrm{n}=$ 10). Specimens used for morphological and meristic analyses are listed in Table S2.

Clarification of terms and measurements used in the paper

Methods and terminology of counts and morphometric parameters are adapted from other published work on rays (Bigelow \& Schroeder 1953, Compagno \& Roberts 1982, Compagno \& Roberts 1984, Nishida \& Nakaya 1990) (Table S3). Measurements were taken as a straight-line distance. Disc width (DW) is the standard measurement of size in rays, and proportional measurements are expressed as \%DW (Table S4). Counts of oral papillae follow Nishida \& Nakaya (1990).
Vertebral and radial counts

The morphological affinities of 3 populations of Dasyatis brevicaudata with the Japanese ray D. matsubarai were evaluated. Counts of radial cartilages and vertebrae were made from radiographs and digital scanning (CT scan), and follow Compagno \& Roberts (1982). Radial counts include all radials with terminal branching. Pectoral radial counts include the radials in the anterior-most extension of the propterygium and the posterior-most extension of the metapterygium. Pelvic radial counts include the 'fused' radials in the anterior-most large compound 'radial'. Vertebral counts included in the analyses include: total vertebral segments; first synarcual free centra; intersynarcual centra; second synarcual and free monospondylous centra combined; diplospondylous tail centra; post-sting centra. Sample sizes vary among analyses. This is due in most cases to poor preservation of specimens (strongly curved wings, closed mouths), or preservation of specimens in mediums inadequate for long-term storage of calcified structures (i.e. formalin). For the larger specimens for which several x-ray films had to be used in order to visualise the entire wing and/or tail sections, a dissection pin was placed at the edge of the frame prior to exposure to ensure a consistent point of reference for all counts.

\section{Data analyses}

\section{Dataset construction and combination of loci}

The data sets for each locus (CO1, cytb, and dloop) were analysed separately to maximise the number of samples in each analysis $(34,30$, and 178 , respectively) and to examine whether the data sets converge on different trees. A combined data set (3160 bp dataset), using 30 sequences available, was also constructed by concatenating all 3 mitochondrial loci (CO1, cytb, dloop) to combine the phylogenetic signal from each data set, and maximise the possibility of finding an optimal topology. A partitioning of homogeneity test was first used to evaluate overall congruence in phylogenetic signal among the 3 loci. The test was implemented in a beta version of PAUP (PAUP v.4.0b10, Swofford 2002), using the heuristic search option with 10 random addition sequence replicates and 100 total replicates to generate the null distribution for the test. Tree bisection-reconnection (TBR) was chosen as a branch-swapping algorithm. Since this test indicated no significant overall 

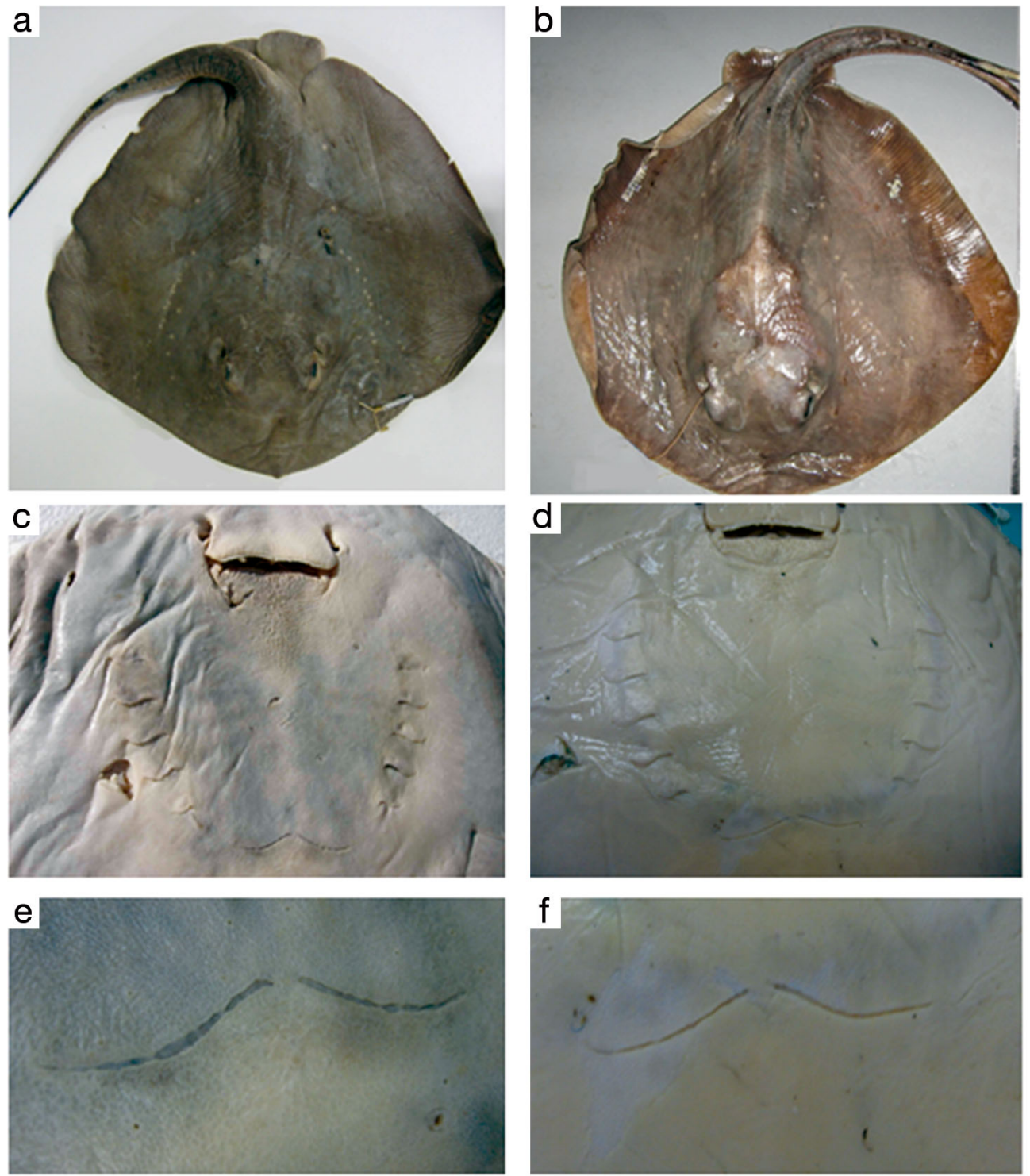

Fig. 2. Dasyatis brevicaudata and D. matsubarai. Photos comparing key morphological traits in D. brevicaudata (left) and $D$. matsubarai (right). (a,b) Dorsal view showing rhomboid disc shape and lateral lines of white spots; (c,d) ventral surface with coracoid groove posterior to 5 th gill opening; $(\mathrm{e}, \mathrm{f})$ close-up of coracoid groove

conflict ( $p=1.00$ ) for the individual partitions (loci), a concatenated dataset was built in MacClade 4.07 (Maddison \& Maddison 2005). The concatenated gene order of the combined dataset was 5'-CO1-cytbdloop-3' for all analyses.

\section{Phylogenetic analyses}

Phylogenetic relationships between the haplotypes found in Dasyatis brevicaudata and D. matsubarai were inferred using distance-based and model-based (neighbour-joining, $\mathrm{NJ}_{\text {; }}$ maximum likelihood, $\mathrm{ML}$ and
Bayesian inference, BA) methods of phylogenetic analyses. The $\operatorname{Tr} \mathrm{N}+\mathrm{I}+\mathrm{G}$ model was selected as the best model of sequence evolution by the ML test in Modeltest 3.7 (Posada \& Crandall 1998) for all datasets. Parameters for the $\operatorname{TrN}+\mathrm{I}+\mathrm{G}$ model were: $-\ln \mathrm{L}=$ 16871.78; K = 7; A:C:G:T = 0.3232, 0.1946, 0.1948, 0.2873 , respectively; $\mathrm{I}=0.5132, \mathrm{G}=0.9124$. The $\mathrm{ML}$ ( $k=100$ bootstrap replicates), and NJ with bootstrapping $(k=1000$ replicates) approaches were based on the described $\operatorname{TrN}+\mathrm{I}+\mathrm{G}$ model parameters using the PHYML extension in Geneious Pro 4.0.2 (Guindon \& Gascuel 2003) and MEGA 4 (Tamura et al. 2007) for each dataset (CO1, cytb, dloop, 3160 bp dataset). 
To calculate posterior probabilities of clades we used the MrBayes extension in Geneious Pro 4.0.2 (Ronquist \& Huelsenbeck 2003). A general time reversible $(G T R+G+I)$ model of substitution with base frequencies was estimated from each dataset for this analysis. To avoid potential problems such as autocorrelation and slow mixing in the Bayesian analysis, it is necessary to perform numerous Markov chain Monte Carlo (MCMC) generations, and in the current study 4 incrementally heated chains were simultaneously run for 1 million MCMC generations for each of the data sets using the program default priors as starting values for the model. Trees were sampled every 1000 generations during the analysis. Bayesian posterior probabilities were obtained from the $50 \%$ majority-rule consensus of all trees sampled after trees from the initial 'burn-in' stage had been removed. The first $10 \%$ of the collected posterior data were discarded to allow 'burn-in' (Ronquist et al. 2005). The phylogenetic trees were visualized and edited where necessary using the Tree View extension within Geneious Pro 4.0.2. Consensus trees are presented. The net nucleotide sequence divergence of the 3160 bp mitochondrial DNA sequences were calculated using DnaSP v.4.5 (Rozas et al. 2003).

\section{Phenotypic variation among populations}

A total of 43 morphological measurements were recorded. Since the sample size (n) was less than the number of variables in the multivariate dataset (p), we used a canonical analysis of principal coordinates (CAP) to try and discriminate between a priori defined groups (Anderson \& Willis 2003). The CAP was run in PRIMER V.6 (Clarke \& Gorley 2006) on the variables without missing values ( $\mathrm{n}=33$, Table S4 in the Supplement) using Euclidean distances in the resemblance matrix. We defined 2 a priori groupings and ran separate analyses. A 'Species' analyses was run to determine whether Dasyatis brevicaudata $(\mathrm{n}=20)$ and $D$. matsubarai $(\mathrm{n}=$ 10) specimens could be reliably distinguished, while the 'Country' grouping allowed us to examine the natural variability in morphological characters (i.e. compare intraspecific vs. interspecific variability) between D. brevicaudata populations (NZ, SA, AUS) and D. matsubarai (JPN). Here, we used the 'leaveone-out allocation' (cross-validation) measure. This removes a single individual (i.e. ray) from the data, then does the CAP discrimination on the remaining data and tries to predict what group the 'removed ray' would be in.

\section{Comparison of genetic and morphological datasets}

In order to compare the levels of divergence in genetic and morphological characters, the pairwise population distances were plotted for both datasets together. For the genetic data, the average sequence divergence between populations was used, while for the morphological data, the patristic distances from the CAP analysis were used as a summary measure across all characters. Datasets could not be compared at the individual level as there was insufficient overlap in the samples with both genetic and morphological data, due to the difficulties of amplifying DNA from formalin-preserved museum specimens.

\section{RESULTS}

\section{Phylogenetic relationships}

$$
\text { Phylogenetic analyses }
$$

Previous phylogenetic analyses of Dasyatidae (Le Port 2009) using mitochondrial CO1, cytb and 16S sequences revealed that Dasyatis thetidis and D. lata were the most closely related species to $D$. brevicaudata and D. matsubarai, and hence these were used as an outgroup in the current analyses. The 2 D. matsubarai samples had the same haplotype for the CO1 and cytb loci, but different haplotypes for the control region. $D$. brevicaudata samples had the same haplotype for CO1, 4 for cytb and 18 for the control region (Fig. 3). Consensus trees for CO1 and the control region agreed in the relationships between the species with $D$. brevicaudata and D. matsubarai coming out as sister clades. However, for cytb, both species do not come out as sister clades. Instead, D. matsubarai is nested within $D$. brevicaudata populations, although the support for this relationship is low due to poor phylogenetic signal (Fig. 3b). The combined $3160 \mathrm{bp}$ dataset showed the greatest resolution (Fig. 4). In this tree, D. brevicaudata and D. matsubarai formed a well-supported clade, which was sister to a clade formed by $D$. thetidis from NZ and SA and D. lata. D. sabina was basal to the other Dasyatis species sequenced (Fig. 4).

Genetic diversity and divergence

Rates of nucleotide divergence were similar across all 3 mtDNA regions e.g. maximum values between Dasyatis brevicaudata and D. matsubarai for CO1 
a

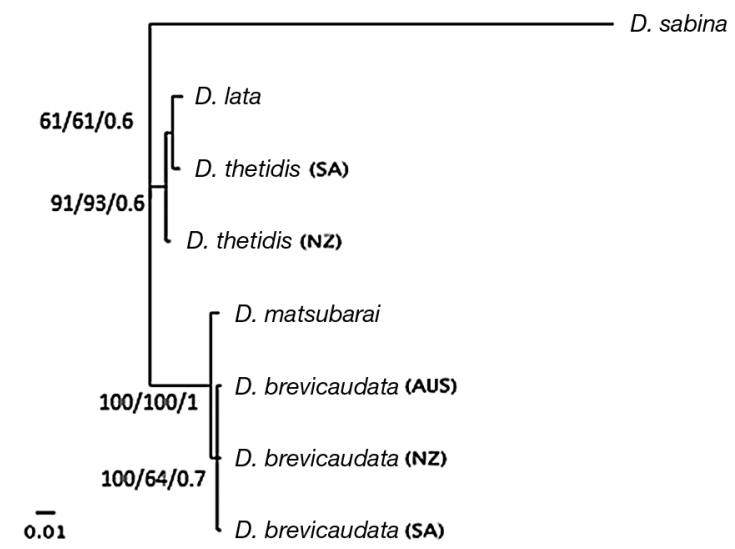

C

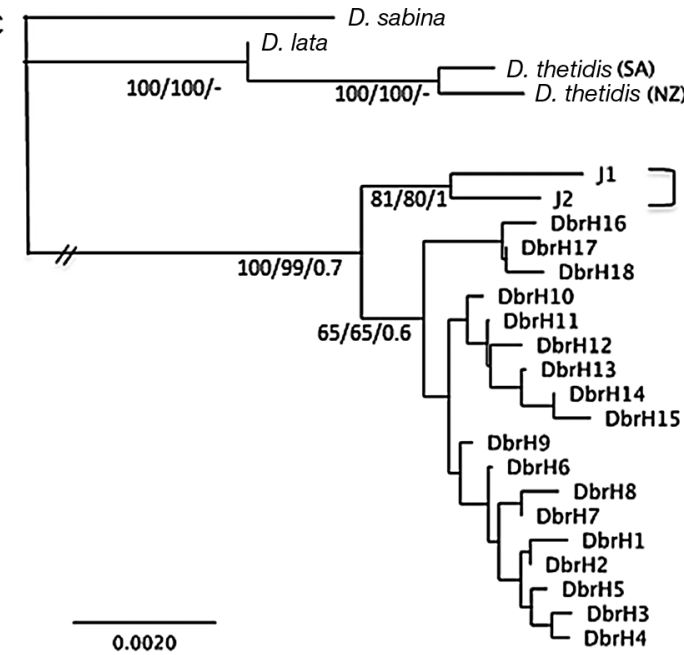

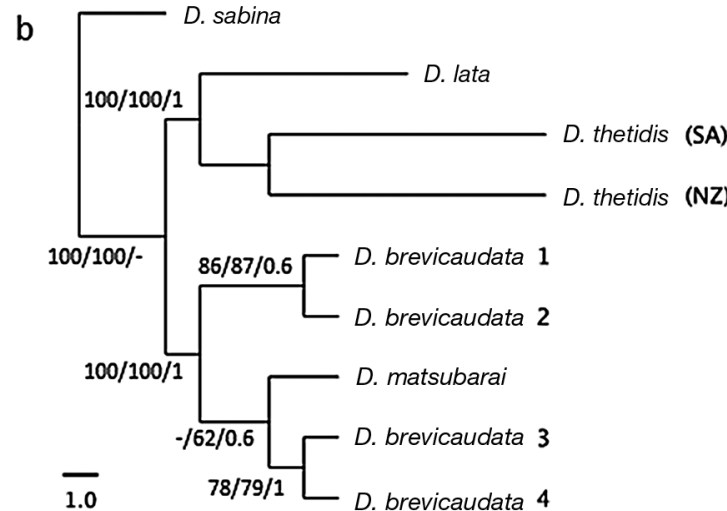

D. matsubarai ]$^{\text {AUS }}$
Fig. 3. Consensus maximum likelihood trees of mitochondrial nucleotide sequences for (a) CO1 ( $\mathrm{n}=32$ ), (b) cytb ( $\mathrm{n}=$ $30)$ and (c) dloop $(\mathrm{n}=176)$ showing the relationships between Dasyatis brevicaudata, D. matsubarai and 3 outgroups. D. brevi- $\quad$ Values on branches reflect neighbour-joincaudata ing/maximum likelihood/Bayesian inference support values, respectively $(>50 \%)$. AUS: Australia; NZ: New Zealand; SA: South Africa. Scale bars: no. of substitutions per site
$(0.35 \%)$, cytb $(0.70 \%)$, dloop $(0.30 \%)$. This does not support the common expectation of a faster rate of substitution for the non-coding dloop region. Within the combined 3160 bp D. brevicaudata/D. matsubarai dataset, 25 variable nucleotide positions were detected, comprised of 16 transitions, 5 transversions, and 1 indel. This produced 16 D. brevicaudata and 2 D. matsubarai haplotypes (Fig. 4). Sequence divergence among $D$. brevicaudata populations ranged between 0.1 and $0.2 \%$, while distances between $D$. brevicaudata and D. matsubarai ranged between 0.3 and $0.5 \%$. Comparatively, the next species most closely related to $D$. brevicaudata in this dataset, $D$. thetidis (NZ and SA) diverged by 5.2 and $5.6 \%$, respectively, and intraspecies sequence divergence for $D$. thetidis was $0.8 \%$ (Table 1 ).

\section{Divergence times}

The net evolutionary rate of the whole elasmobranch mtDNA has been estimated at $~ 0.31 \% \mathrm{Myr}^{-1}$
(Dunn et al. 2003) and the cytb third codon silent rate of substitution estimated at $\sim 0.71 \% \mathrm{Myr}^{-1}$ (Martin 1995). We estimated divergence times between and within species for the $3160 \mathrm{bp}$ dataset by using 2 rates of control region divergence reported for shark lineages (0.8 and 0.67\% $\mathrm{Myr}^{-1}$ ) (Duncan et al. 2006, Schultz et al. 2008). The 3 Dasyatis brevicaudata lineages with sequence divergence values ranging between 0.1 and $0.2 \%$ may have diverged only 62500 to 149000 yr ago. On the other hand, nucleotide divergences ranging from 0.3 and $0.5 \%$ between $D$. brevicaudata and D. matsubarai suggest these 2 species found either side of the tropics may have evolved in isolation for 187000 to $373000 \mathrm{yr}$.

\section{Morphological differences}

The CAP analysis on 33 morphological variables using 'Species' as the grouping variable was able to distinguish Dasyatis brevicaudata from D. matsubarai specimens with a high degree of accuracy $(87 \%)$ 


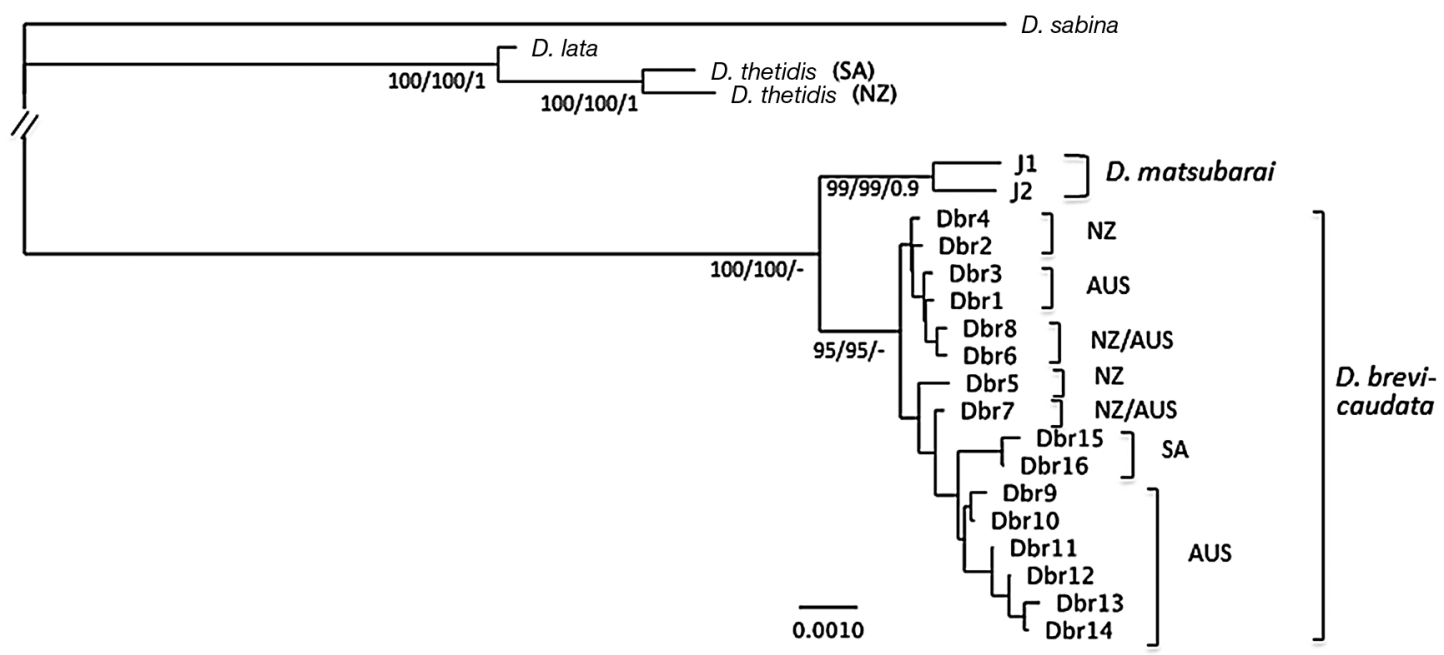

Fig. 4. Consensus maximum likelihood tree of the combined mitochondrial nucleotide sequences (3160 bp dataset: CO1/cytb/dloop) showing relationships between Dasyatis brevicaudata $(\mathrm{n}=28)$, D. matsubarai $(\mathrm{n}=2)$ and 3 outgroups. Details as in Fig. 3

(Fig. S1 in the Supplement). Only 4 out of 30 individuals were incorrectly classified $(3 \mathrm{D}$. brevicaudata and $1 \mathrm{D}$. matsubarai). On the other hand, when the variable 'Country' was used, 19 out of $30(63 \%)$ of individuals were correctly classified (Fig. 5). Interestingly, based on morphological characters, 3 groups could be discriminated in the latter analysis: NZ ( $D$. brevicaudata), SA/AUS (D. brevicaudata), and JPN (D. matsubarai), suggesting that natural phenotypic variations may be very similar intra- and interspecifically. Using a correlation plot, the variables IPD (interpectoral distance) and HED (horizontal eye diameter) were the most useful in distinguishing groups NZ and JPN, while IOW (interorbital width), SPV (prepelvic length), DL2 (disc length including pelvics), INW2 (internasal width-posterior) appear to be the most useful in discriminating between groups NZ and SA/AUS, and PVL (pelvic fin length) and VTL (ventral tailfold length) for groups SA/AUS and JPN (Fig. 5, Table S3 in the Supplement).
Meristic counts were comparable between Dasyatis brevicaudata individuals from the $3 \mathrm{D}$. brevicaudata Southern Hemisphere populations and $D$. matsubarai from JPN (Table 2). Total number of vertebral segments ranged between 154 and 175 in $D$. brevicaudata and between 160 and 172 in D. matsubarai. Also, the total number of pectoral and pelvic radials did not differ between $D$. brevicaudata and D. matsubarai specimens (Table 2).

\section{Genetic and morphological concordance}

Overall, there appears to be concordance between the genetic and morphological datasets, in that both can distinguish between the 2 taxa, but that they have not diverged greatly. When the divergences between the various populations are compared across the 2 datasets, some discordance is observed (Fig. 6). The New Zealand population is particularly

Table 1. Pairwise comparisons of genetic distances (\% divergence, Tamura-Nei model) for Dasyatis brevicaudata, D. matsubarai and the outgroups in the 3160 bp dataset. AUS: Australia; NZ: New Zealand; SA: South Africa. Sample size in parentheses

\begin{tabular}{|c|c|c|c|c|c|c|c|c|c|}
\hline & & \multicolumn{3}{|c|}{ D. brevicaudata } & \multirow{2}{*}{$\begin{array}{c}\text { D. matsubarai } \\
\text { (2) }\end{array}$} & \multicolumn{2}{|c|}{ D. thetidis } & \multirow{2}{*}{$\begin{array}{l}\text { D. lata } \\
\text { (1) }\end{array}$} & \multirow{2}{*}{$\begin{array}{c}\text { D. sabina } \\
\text { (1) }\end{array}$} \\
\hline & & $\begin{array}{c}\text { AUS } \\
(10)\end{array}$ & $\begin{array}{l}\text { NZ } \\
(12)\end{array}$ & $\begin{array}{l}\text { SA } \\
(6)\end{array}$ & & $\begin{array}{l}\text { NZ } \\
(2)\end{array}$ & $\begin{array}{l}\text { SA } \\
(2)\end{array}$ & & \\
\hline \multirow[t]{3}{*}{ D. brevicaudata } & AUS & - & & & & & & & \\
\hline & NZ & 0.07 & - & & & & & & \\
\hline & SA & 0.09 & 0.18 & - & & & & & \\
\hline D. matsubarai & & 0.35 & 0.37 & 0.49 & - & & & & \\
\hline \multirow[t]{2}{*}{ D. thetidis } & NZ & 5.60 & 5.53 & 5.60 & 5.76 & - & & & \\
\hline & SA & 5.29 & 5.22 & 5.33 & 5.46 & 0.85 & - & & \\
\hline D. lata & & 5.47 & 5.43 & 5.56 & 5.60 & 1.53 & 1.60 & - & \\
\hline D. sabina & & 9.56 & 9.56 & 9.54 & 9.60 & 11.43 & 11.37 & 11.63 & - \\
\hline
\end{tabular}



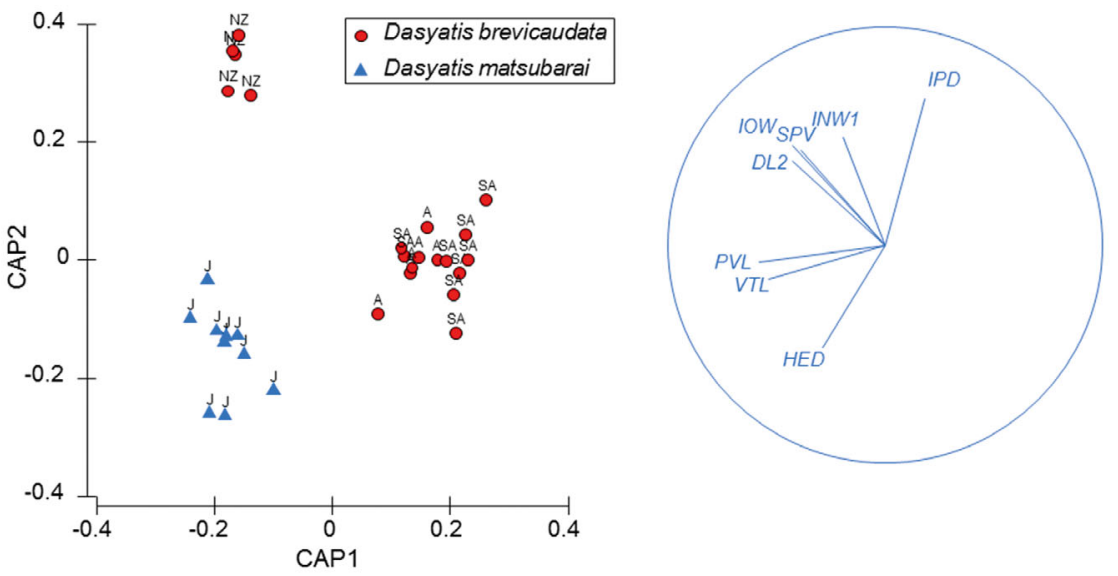

Fig. 5. Relative positions in plots of first 2 canonical functions of specimens (Dasyatis brevicaudata $[\mathrm{n}=20]$ and D. matsubarai $[\mathrm{n}=10]$ ) subjected to canonical analysis of principal coordinates (CAP) on 33 morphological characters using the variable 'Country'. A: Australia; J: Japan; NZ: New Zealand; SA: South Africa. The correlations ( $r>0.50$ ) of the 4 groupings with the 2 CAP axes are presented to the right. See Table S3 in the Supplement for character abbreviations

interesting, in that it appears to have diverged morphologically to a similar degree as Dasyatis matsubarai, while maintaining relatively close genetic similarity to the other $D$. brevicaudata populations.

\section{DISCUSSION}

We have confirmed here that Dasyatis brevicaudata and $D$. matsubarai are distinguishable both genetically and morphologically. We have also confirmed that, as suspected, these are sister taxa. How- ever, the levels of inter-specific divergence seen here are much smaller than expected, suggesting that the antitropical species $D$. brevicaudata and $D$. matsubarai are in the beginning stages of diverging into allopatric lineages.

\section{Divergence between Dasyatis brevicaudata and $D$. matsubarai}

Molecular data are particularly applicable for taxa that have diverged recently and exhibit limited variation in morphological traits (Avise 1994). It has been suggested in cetaceans that at least 2 lines of evidence indicating irreversible divergence are needed to distinguish species (e.g. genetic and morphological) (Reeves et al. 2004). In the present study, evidence from mtDNA (CO1, cytb, dloop), as well as morphometric data strongly support that the 2 described stingray species are distinct, but very closely related. However, several aspects of these results are worth discussing further.

Mitochondrial CO1 barcodes have been used successfully to discriminate elasmobranch species (Ward et al. 2008a). CO1 results from this study revealed a detectable divergence between Dasyatis matsubarai and $D$. brevicaudata (minimum number of fixed base differences of $2[0.4 \%]$ ) compared to no divergence between all $D$. brevicaudata populations. However,

Table 2. Dasyatis brevicaudata and D. matsubarai. Vertebral counts. Information on size range (disc width in mm), sex and total numbers of individuals examined are provided below population headings. AUS: Australia; NZ: New Zealand; JPN: Japan; SA: South Africa; M: male; F: female; na: not applicable

\begin{tabular}{|lcccc|}
\hline Counts & $\begin{array}{c}\text { D. brevicaudata (NZ) } \\
290.0-540.0(4 \mathrm{~F})\end{array}$ & $\begin{array}{c}\text { D. brevicaudata (AUS) } \\
325.0-673.0(1 \mathrm{M}, 3 \mathrm{~F})\end{array}$ & $\begin{array}{c}\text { D. brevicaudata (SA) } \\
390.0-750.0(5 \mathrm{M}, 4 \mathrm{~F})\end{array}$ & $\begin{array}{c}\text { D. matsubarai (JPN) } \\
367.0-470.0(4 \mathrm{M}, 6 \mathrm{~F})\end{array}$ \\
\hline Oral papillae & na & $7(\mathrm{n}=1)$ & $5(\mathrm{n}=2)$ & $5-11(\mathrm{n}=9)$ \\
1st synarcual free centra & $1-2$ & $0-2$ & $2-3$ & $3-6$ \\
Intersynarcual centra & $6-7$ & $5-6$ & $5-7$ & $31-36$ \\
2nd synarcual + monosp. & $34-36$ & $31-39$ & $27-39$ & $81-85$ \\
Pre-sting diplospondylous & $71-84$ & $83-88$ & $72-88$ & $41-47$ \\
vertebrae & & & & $122-132$ \\
Post-sting centra & $38-56$ & $34-41$ & $40-50$ & $160-172$ \\
Total diplospondylous & $109-140$ & $117-129$ & $116-138$ & $54-57$ \\
Total vertebral segments & $164-169$ & $156-174$ & $46-56$ & $15-17$ \\
Propterygial radials (left) & $52-56$ & $54-56$ & $11-18$ & $54-56$ \\
Mesopterygial radials (left) & $15-16$ & $12-16$ & $48-56$ & $123-125$ \\
Metapterygial radials (left) & $54-56$ & $50-55$ & $22-25$ & $24-127$ \\
Total pectoral radials (left) & $121-126$ & $120-124$ & $23-27$ & $23-26$ \\
Pelvic radials (left) & $25-27$ & $22-26$ & & \\
Pelvic radials (right) & 24 & $22-26$ & & \\
\hline
\end{tabular}




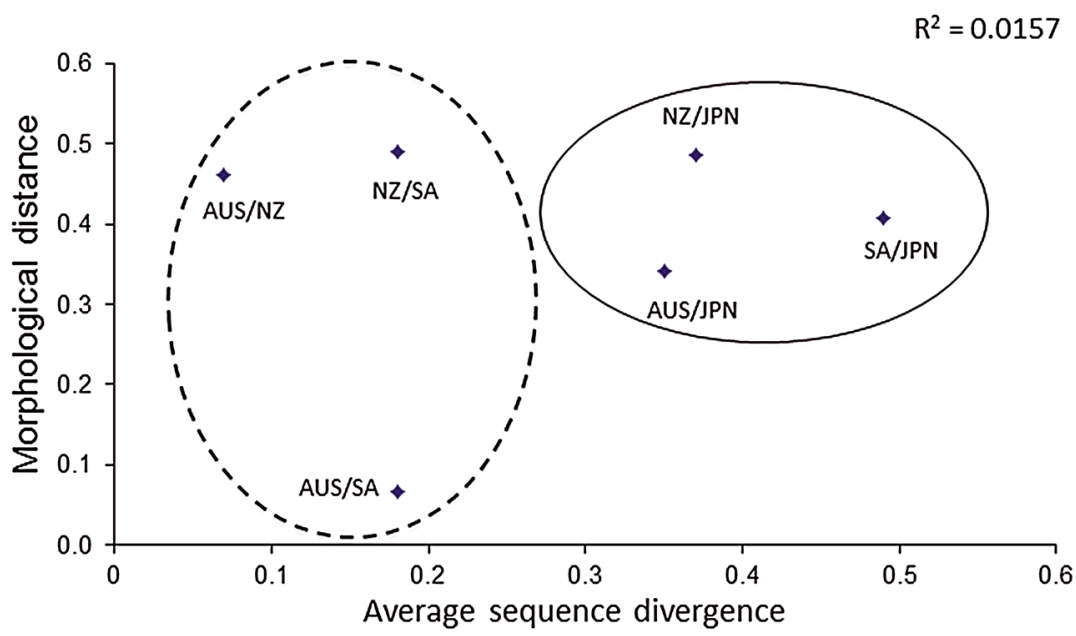

Fig. 6. Pairwise comparisons of the levels of divergence in genetic and morphological characters between Dasyatis brevicaudata lineages and D. matsubarai. For the genetic data, the average sequence divergence between populations was used, while for the morphological data, we used the average patristic distances between groups from the CAP analysis. Intra-specific (dashed line) and inter-specific (continuous line) groupings are highlighted these values are much more similar to intra-species divergences (average $0.37 \%$ ) rather than inter-species differences (average among congeners of $7.5 \%$ ) reported in over 200 shark and ray species (Ward et al. 2008a, Cerutti-Pereyra et al. 2012). Similarly, the combined 3160 bp mtDNA dataset suggests that D. matsubarai is not greatly more divergent from $D$. brevicaudata than are Southern Hemisphere regional populations of $D$. brevicaudata from each other. A comparison among these 2 species and other dasyatids examined in this study or among closely related elasmobranchs in other published studies, shows that the divergence between $D$. brevicaudata and D. matsubarai $(0.3$ to $0.5 \%)$ does not fall within the range expected between different species. It is also much lower than mitochondrial control region divergences reported for closely related and morphologically similar batoids (e.g. thornback ray Raja clavata vs. biscuit skate R. straeleni, 1.8\%, Pasolini et al. 2011, and Gulf of California vs. Pacific shovelnose guitarfish Rhinobatos productus, 2.5\%, Sandoval-Castillo et al. 2004). Therefore, genetic evidence from 3 mtDNA markers showing such low levels of inter-specific divergence suggests that D. matsubarai and D. brevicaudata have likely diverged very recently, and are in the early stages of allopatric speciation.

Despite considerable sampling efforts, we were able to obtain DNA sequences from only 2 Dasyatis matsubarai specimens (from widely separated locations in the Japanese range, ca. $1000 \mathrm{~km}$ apart), as all individuals of this species used in the morphological analyses were formalin-preserved. This clearly prevents us from making an accurate estimate of the full genetic diversity within the taxon. However, given the close similarity of these sequences $(<0.1 \%$ divergence), their considerably greater divergence from all Dasyatis brevicaudata sequences (0.3 to $0.5 \%)$, and the very strong support for the reciprocal monophyletic relationship between the taxa, we are very confident of our major conclusions about the close sister relationship between these taxa.

Another line of evidence (morphological and meristic data) was used in this study to assess the status of Dasyatis matsubarai and D. brevicaudata. Multivariate analyses of 33 morphological characters were useful in discriminating between the 2 species, although once again, the inter-specific variability in morphological characters was similar to that between $D$. brevicaudata populations. Interestingly, no differences in meristic counts between species were found. These subtle phenotypic changes are all the more interesting given that we estimate that these species diverged between 187000 and $373000 \mathrm{yr}$ ago, suggesting that these rays could be evolving very slowly. Morphological stasis has been reported in marine organisms (RochaOlivares et al. 2001), and may be common in rays and skates (McEachran \& Dunn 1998, Pasolini et al. 2011).

The comparison of genetic and morphological data in our study reveals that, not unexpectedly, the geographically separated populations of these taxa have not diverged at the same rate in genetic and morphological characters. The New Zealand population has apparently diverged morphologically more than expected. Mayr (1954) described geographical speciation as a process leading over time to a continuum of stages of increasing divergence. $D$. brevicaudata and $D$. matsubarai may be only part-way through this process.

\section{Migration and distribution patterns: evolutionary history}

Our data from the combination of 3 mitochondrial loci suggest that Dasyatis brevicaudata and D. mat- 
subarai diverged during the Pleistocene (187000 to 373000 yr ago). However, it is unclear what evolutionary process led to this divergence, and ultimately to their antitropical distribution. Our genetic and morphological data permit us to reject some evolutionary scenarios, but not all. Firstly, the genetic data reject the possibility that there is any ongoing connection between the 2 taxa, as there are no shared or closely related haplotypes, and they are clearly reciprocally monophyletic lineages. We can also reject the scenario that there has been very recent colonization of one hemisphere, as there is no evidence of greatly reduced genetic diversity within either lineage, or of paraphyly, which would be expected in such a scenario.

Two other major scenarios have been proposed to explain antitropical distributions. Older transequatorial dispersal during periods of glaciation has been widely proposed as a mechanism for the formation of antitropical distributions in fishes (Randall 1981, Graves 1998, Benzie 1999, Burridge 2002, Liu et al. 2006). However, fish have high larval dispersal potentials (Graves 1998), while stingrays (Myliobatiformes), on the other hand, as coastal bentho-pelagic elasmobranchs, have comparatively low dispersal capabilities. An alternative scenario that has been invoked for these transequatorial divergences is the vicariant isolation of ancestral populations occupying the tropics during the warming of interglacial phases (the 'tropical extinction' hypothesis, Briggs 2003). Unfortunately, these alternative scenarios are not easily distinguished by molecular data, as both have similar genetic outcomes. There is no evidence for long-distance migrations or deepwater crossings in Dasyatis brevicaudata (Le Port et al. 2008, Last \& Stevens 2009). However, the occurrence of $D$. brevicaudata at remote offshore locations (e.g. West Norfolk Ridge, Gascoyne Seamount) with deep bottom depths ( $\geq 1000 \mathrm{~m}$ ) (Clark 1988, W. White pers. comm.) suggests the use of these areas as stepping-stones in past or current migrations. We suggest that the current disjunct distribution of $D$. brevicaudata and $D$. matsubarai may be the result of rare long-distance migrations across deep tropical waters during cooler periods, when this species' distribution would likely have extended much further into tropical waters, and lowered sea levels would have provided many more shallow stepping-stones. Additional D. matsubarai samples, and mitochondrial and nuclear DNA analyses would be required to further test these scenarios.

Regardless of the exact mechanism, it is clear that Dasyatis brevicaudata and D. matsubarai are now completely reproductively isolated. They have diverged little in either molecular or morphological characters, but it appears we have caught them in the beginning stages of diverging into allopatric lineages. It is possible that a similar process of allopatric divergence has driven the speciation process in other Dasyatis lineages.

Acknowledgements. The authors thank the following people for their invaluable help: A. Stewart and C. Struthers (Te Papa Museum, Wellington, New Zealand), C. Duffy (Department of Conservation, Auckland, New Zealand), N. Hannam (Kelly Tarlton's Underwater World, Auckland, New Zealand), D. Egli (GIZ, Philippines), staff at Melbourne Aquarium, P. Last, W. White, D. Gledhill and A. Graham (CSIRO Marine and Atmospheric Research, Hobart, Tasmania), L. Compagno, M. Bougaardt, E. Hoensen (Iziko South African Museum, Cape Town, South Africa), M. Smale \& L. Singh (Bayworld Aquarium, Port Elisabeth, South Africa), M. Farquhar \& C. Taylor (Two Oceans Aquarium, Cape Town, South Africa), S. Basson (St Georges Hospital, Port Elizabeth, South Africa), H. Imamura \& K. Nakaya (Hokkaido University, Hakodate, Japan), H. Ishihara (Taiyo Engineering Co. Ltd., Tokyo, Japan), D. Chapman (Stony Brook University, New York, USA). We also thank 3 anonymous reviewers for their constructive comments on this manuscript.

\section{LITERATURE CITED}

Anderson MJ, Willis TJ (2003) Canonical analysis of principal coordinates: a useful method of constrained ordination for ecology. Ecology 84:511-525

Avise JC (1994) Molecular markers, natural history and evolution. Chapman \& Hall, New York, NY

> Benavides MT, Feldheim KA, Duffy CA, Wintner S and others (2011) Phylogeography of the copper shark (Carcharhinus brachyurus) in the southern hemisphere: implications for the conservation of a coastal apex predator. Mar Freshw Res 62:861-869

$>$ Benzie JAH (1999) Major genetic differences between crown-of-thorns starfish (Acanthaster planci) populations in the Indian and Pacific Oceans. Evolution 53: 1782-1795

Bigelow HB, Schroeder WC (1953) Fishes of the western North Atlantic: Sawfishes, guitarfishes, skates and rays. Sears Foundation for Marine Research, Yale University, New Haven, CT

Briggs JC (2003) Marine centres of origin as evolutionary engins. J Biogeogr 30:1-18

$>$ Burridge CP (2002) Antitropicality of Pacific fishes: molecular insights. Environ Biol Fishes 65:151-164

> Cerutti-Pereyra F, Meekan MG, Wei NWV, O'Shea O, Bradshaw CJA, Austin CM (2012) Identification of rays through DNA barcoding: an application for ecologists. PLoS ONE 7:e36479

Chow S, Kishino H (1995) Phylogenetic relationships between tuna species of the genus Thunnus (Scombridae: Teleostei): inconsistent implications from morphology, nuclear and mitochondrial genomes. J Mol Evol 41: 741-748

Clark MR (1988) Records of fishes from the West Norfolk Ridge north-west of New Zealand. NZ J Zool 15:415-422 
Clarke KR, Gorley RN (2006) PRIMER v6: user manual/tutorial. PRIMER-E, Plymouth

- Compagno LJV, Roberts TR (1982) Freshwater stingrays (Dasyatidae) of southeast Asia and New Guinea, with description of a new species of Himantura and reports of unidentified species. Environ Biol Fishes 7:321-339

Compagno LJV, Roberts TR (1984) Marine and freshwater stingrays Dasyatidae of West Africa with description of a new species. Proc Calif Acad Sci 43:283-300

Compagno LJV, Ebert DA, Smale MJ (1989) Guide to the sharks and rays of Southern Africa. Struik Publishers, Cape Town

Compagno LJV, Dando M, Fowler SL (2005) Sharks of the World. Princeton University Press, Princeton, NJ

> Douady CJ, Dosay M, Shivji MS, Stanhope MJ (2003) Molecular phylogenetic evidence refuting the hypothesis of Batoidea (rays and skates) as derived sharks. Mol Phylogenet Evol 26:215-221

> Duncan KM, Martin AP, Bowen BW, Couet HGD (2006) Global phylogeography of the scalloped hammerhead shark (Sphyrna lewini). Mol Ecol 15:2239-2251

> Dunn KA, McEachran JD, Honeycutt RL (2003) Molecular phylogenetics of myliobatiform fishes (Chondrichthyes: Myliobatiformes), with comments on the effects of missing data on parsimony and likelihood. Mol Phylogenet Evol 27:259-270

- Graves JE (1998) Molecular insights into the population structures of cosmopolitan marine fishes. J Hered 89: 427-437

Guindon S, Gascuel O (2003) A simple, fast and accurate algorithm to estimate large phylogenies by maximum likelihood. Syst Biol 52:696-704

Hubbs CL (1952) Antitropical distribution of fishes and other organisms. Symposium on the problems of bipolarity and of pantemperate faunas. Proc 7th Pac Sci Congr 3:324-329

> Human BA, Owen EP, Compagno LJV, Harley EH (2006) Testing morphologically based phylogenetic theories within the cartilaginous fishes with molecular data, with special reference to the catshark family (Chondrichthyes; Scyliorhinidae) and the interrelationships within them. Mol Phylogenet Evol 39:384-391

$>$ Hutton FW (1875) Descriptions of new species of New Zealand fish. Ann Mag Nat Hist 16:313-317

Keeney DB, Heist EJ (2006) Worldwide phylogeography of the blacktip shark (Carcharhinus limbatus) inferred from mitochondrial DNA reveals isolation of western Atlantic populations coupled with recent Pacific dispersal. Mol Ecol 15:3669-3679

Kitamura T, Takemura A, Watabe S, Taniuchi T, Shimizu M (1996) Molecular phylogeny of the sharks and rays of superorder Squalea based on mitochondrial cytochrome $b$ gene. Fish Sci 62:340-343

Last PR, Stevens JD (2009) Sharks and rays of Australia. CSIRO Publishing, Collingwood

Le Port A (2009) Phylogenetics, phylogeography and behavioural ecology of short-tailed (Dasyatis brevicaudata) and longtail ( $D$. thetidis) stingrays. PhD dissertation, University of Auckland

> Le Port A, Lavery S (2012) Population structure and phylogeography of the short-tailed stingray, Dasyatis brevicaudata (Hutton 1875), in the southern hemisphere. J Hered 103:174-185

> Le Port A, Sippel T, Montgomery JC (2008) Observations of mesoscale movements in the short-tailed stingray, Dasy- atis brevicaudata from New Zealand using a novel PSAT tag attachment method. J Exp Mar Biol Ecol 359:110-117

Lee C, Joo D (1996) Synopsis of the family Dasyatidae (Elasmobranchii, Rajiformes) from Korea. J Korean Fish Soc 29:745-753

Liu JX, Gao TX, Zhuang ZM, Jin XS, Yokogawa K, Zhang YP (2006) Late Pleistocene divergence and subsequent population expansion of two closely related fish species, Japanese anchovy (Engraulis japonicus) and Australian anchovy (Engraulis australis). Mol Phylogenet Evol 40: 712-723

Maddison WP, Maddison DR (2005) MacClade: analysis of phylogeny and character evolution, Version 4.07. Sinauer Associates, Sunderland, MA.

> Martin AP (1995) Mitochondrial DNA sequence evolution in sharks: rates, patterns, and phylogenetic inferences. Mol Biol Evol 12:1114-1123

- Mayr E (1954) Geographic speciation in tropical echinoids. Evolution 8:1-18

> McEachran JD, Dunn KA (1998) Phylogenetic analysis of skates, a morphologically conservative clade of elasmobranchs (Chondrichthyes: Rajidae). Copeia 1998:271-290

Miyosi Y (1939) Description of three new species of elasmobranchiate fishes collected at Hyuga Nada, Japan. Bull Biogeograph Soc Jap 9:91-97

Nishida K, Nakaya K (1990) Taxonomy of the genus Dasyatis (Elasmobranchii, Dasyatididae) from the North Pacific. In: Pratt HL Jr, Gruber SH, Toru T (eds) Elasmobranchs as living resources: advances in the biology, ecology, systematics, and the status of the fisheries. NOAA Technical Report NMFS 90. US Department of Commerce, p 327-346

Palumbi SR (1996) Nucleic Acids II: the Polymerase Chain Reaction. In: Hillis DM, Moritz C, Mable BK (eds) Molecular systematics. Sinauer Associates, Sunderland, MA, p 205-248

Pasolini P, Ragazzini C, Zaccaro Z, Cariani A and others (2011) Quaternary geographical sibling speciation and population structuring in the Eastern Atlantic skates (suborder Rajoidea) Raja clavata and R. straeleni. Mar Biol 158:2173-2186

> Posada D, Crandall KA (1998) Modeltest: testing the model of DNA substitution. Bioinformatics 14:817-818

Randall JE (1981) Examples of antitropical and antiequatorial distribution of Indo-West Pacific fishes. Pac Sci 35:197-209

Reeves RR, Perrin WF, Taylor BL, Baker CS, Mesnick SL (2004) Report of the workshop on shortcomings of cetacean taxonomy in relation to needs of conservation and management, April 30-May 2, 2004 La Jolla, California. US Dept of Commerce, National Oceanic and Atmospheric Administration, National Marine Fisheries Service

Rocco L, Liguori I, Costagliola D, Morescalchi MA, Tinti F, Stingo V (2007) Molecular and karyological aspects of Batoidea (Chondrichthyes, Elasmobranchi) phylogeny. Gene 389:80-86

> Rocha-Olivares A, Fleeger JW, Foltz DW (2001) Decoupling of molecular and morphological evolution in deep lineages of a meiobenthic harpacticoid copepod. Mol Biol Evol 18:1088-1102

Ronquist F, Huelsenbeck JP (2003) MRBAYES 3: Bayesian phylogenetic inference under mixed models. Bioinformatics 19:1572-1574

Ronquist F, Huelsenbeck JP, van der Mark P (2005) MrBayes 
3.1 Manual. http://www.molecularevolution.org/molevol files/mrbayes/mb3.1_manual.pdf

Rozas J, Sanchez-DelBarrio JC, Messeguer X, Rozas R (2003) DnaSP, DNA polymorphism analyses by the coalescent and other methods. Bioinformatics 19:2496-2497

Saiki RK, Gelfand DH, Stoffel S, Scharf SJ and others (1988) Primer-directed enzymatic amplification of DNA with a thermostable DNA polymerase. Science 239:487-491

Sandoval-Castillo J, Rocha-Olivares A, Villavicencio-Garayzar C, Balart E (2004) Cryptic isolation of Gulf of California shovelnose guitarfish evidenced by mitochondrial DNA. Mar Biol 145:983-988

Schultz JK, Feldheim KA, Gruber SH, Ashley MV, Mcgovern TM, Bowen BW (2008) Global phylogeography and seascape genetics of the lemon sharks (genus Negaprion). Mol Ecol 17:5336-5348

Swofford DL (2002) PAUP*: phylogenetic analysis using parsimony ( ${ }^{*}$ and other methods), 4.0b.10. Sinauer Associates, Sunderland, MA

Editorial responsibility: Thomas Turner,

Albuquerque, New Mexico, USA
Tamura K, Dudley J, Nei M, Kumar S (2007) MEGA4: Molecular Evolutionary Genetics Analysis (MEGA) software version 4.0. Mol Biol Evol 24:1596-1599

> Veríssimo A, McDowell JR, Graves JE (2010) Global population structure of the spiny dogfish Squalus acanthias, a temperate shark with an antitropical distribution. Mol Ecol 19:1651-1662

- Ward RD, Zemlak TS, Innes BH, Last PR, Hebert PDN (2005) DNA barcoding Australia's fish species. Philos Trans R Soc Lond B Biol Sci 360:1847-1857

Ward RD, Holmes BH, White WT, Last PR (2008a) DNA barcoding Australasian chondrichthyans: results and potential uses in conservation. Mar Freshw Res 59:57-71

Ward RD, Holmes BH, Zemlak TS, Smith PJ (2008b) DNA barcoding discriminates spurdogs of the genus Squalus. In: Last PR, White WT, Pogonoski JJ (eds) Descriptions of new dogfishes of the genus Squalus (Squaloidea: Squalidae) CSIRO Marine and Atmospheric Research Paper 014. CSIRO, Hobart, p 117-130

Submitted: January 28, 2013; Accepted: June 13, 2013 Proofs received from author(s): September 13, 2013 